\title{
Structure and chemotactic activity of peptides isolated from the venom sac of Vespinae
}

\author{
Yoshio Tsukamoto ${ }^{1}$, Sachiko Fukutani ${ }^{1}$, Yutaka Morikawa ${ }^{1}$, Heizo Fujimoto ${ }^{1}$, \\ Yasunori Tanaka ${ }^{1}$, Masakazu Mori ${ }^{1}$, Tadashi Yasuhara ${ }^{2}$, Terumi Nakajima ${ }^{2}$, \\ Chieko Kitada ${ }^{3}$ and Masahiko Fujino ${ }^{3}$ \\ ${ }^{1}$ Department of Pharmacology, Osaka Dental University, \\ 1-47, Kyobashi, Higashi-ku, Osaka 540 \\ ${ }^{2}$ Institute for Medical Engineering, Tokyo Medical and Dental University, \\ Chiyoda-ku, Tokyo 101 \\ ${ }^{3}$ Central Research Division, Takeda Chemical Industries, Ltd., \\ Yodogazva-ku, Osaka 532
}

[Accepted for publication: September 21, 1985]

Key words: Wasp venoms / peptides / chemotaxis/leucocytes

\section{Introduction}

It has been already reported that tridecapeptide amides were isolated from the venom of several species of Vespinae. However, the biological activities of these peptides have not yet been made clear. It was only reported that, the peptide (Crabrolin), which was isolated in U.S.A. from Vespa crabro, stimulate the degranulation of granulocytes, and no biological activity has been found for the peptide isolated in U.S.S.R. from Vespa orientalis.

Recently, it was found that one of these peptides were able to stimulate chemotaxis in leucocytes. This vespid chemotactic peptide was isolated from Vespa tropica ${ }^{1)}$

Therefore, we investigated all of these peptides and detected significant levels of chemotactic activity for mononuclear leucocytes (MNL) and polymorphonuclear leucocytes (PMNL).

\section{Materials and Methods}

The venom sac of several species of Vespinae, Vespa tropica (Japanese name is Himesuzumebachi, Ves-T), Vespa mandarinia (Ohsuzumebachi, Ves-M), Vespa analis (Kogatasuzumebachi, Ves-A), Vespa xanthoptera (Kiirosuzumebachi, Ves-X), Para- vespula lewisii (Jibachi, Ves-L) and Icaria sp. (Ves-I), were homogenized in $50 \%$ $\mathrm{CH}_{3} \mathrm{CN}$ and the homogenates were centrifuged at $1,500 \times \mathrm{g}$ for $10 \mathrm{~min}$. From the supernatants, the peptides were isolated by LS-410 ODS column chromatography with the $\mathrm{CH}_{3} \mathrm{CN}$ gradient $(10-50 \%)$ elution system. The sequences of these peptides are shown in Table 1.

MNLs and PMNLs were separated from human peripheral blood by the Ficoll-Paque

Table 1 The sequence of vespid peptides

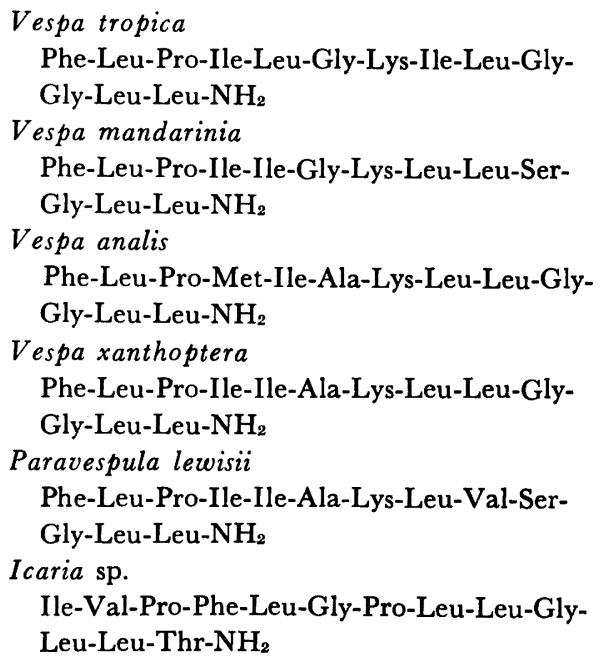


method, and chemotaxis assay was performed by using a modification of a method described by Falk et $a l_{.}{ }^{2,3)}$. A multi-well chemotaxis chamber (Neuro Probe) was used with a polycarbonate membrane filter (Neuro Probe) with a pore size of $3 \mu \mathrm{m}$ for PMNLs, and $5 \mu \mathrm{m}$ for MNLs.

After incubation, the filter was removed, fixed and stained. Leucocytes that had migrated through the filter were counted in 20 oil immersion fields at $\times 1,000$ magnification and expressed as cells per oil immersion field (cells/oif).

\section{Results and Discussion}

Vespid peptides in the varying concentrations of 0.1 to $50 \mathrm{nmol} / \mathrm{ml}$ were added to the lower wells of the chemotaxis chamber and the MNL suspension was added to the upper wells, and incubated at $37^{\circ} \mathrm{C}$ for 90 min. Ves-T, M, A, X, L and I showed significant levels of chemotactic activities for MNL. Although the synthetic chemoattractant, N-folmylmethionyl-leucyl-phenylalanine $\left(10^{-8} \mathrm{M}\right)$, induced chemotactic ratio of 138 cells/oif at concentration of $10 \mathrm{nmol} / \mathrm{ml}$ and 4 cells/oif by the buffer control, most of vespid peptides elicited more than 150 cells/ oif at concentrations of 1.0 to $20 \mathrm{nmol} / \mathrm{ml}$. Especially, at 2.0 to $10 \mathrm{nmol} / \mathrm{ml}$, activities of Ves-T, M, X and A were notable (Fig. 1).

The experiments were performed to determine whether leucocyte migration was merely representative of hyperkinesis or was indeed a directional migration towards these peptides $^{4)}$, however, the result of these experiments showed that MNLs and PMNLs migration occurred only in the presence of a positive stimulatory gradient.

Moreover, several peptides were synthesized from the amino sequence assay of vespid peptides, and tested for leucocyte chemotaxis. Some of them, such as Phe-Leu-ProIle-Leu-Gly-Lys-Ile-Leu-Gly-Gly-Leu-Leu$\mathrm{NH}_{2}$, Lys-Ile-Leu-Gly-Gly-Leu-Leu-NH , Gly-Leu-Leu- $\mathrm{NH}_{2}$, Leu-Gly-Gly-Leu-Leu$\mathrm{NH}_{2}$ and Lys-Ile-Leu-Gly, induced varying degrees of migration in PMNLs or MNLs.

Thus, tridecapeptide amides isolated from the venom sac of several species of Vespinae can cause directional migration of PMNLs and MNLs. Further, synthetic peptides and their fragments have active effect on the migration of leucocytes, equal to or higher than vespid peptides.

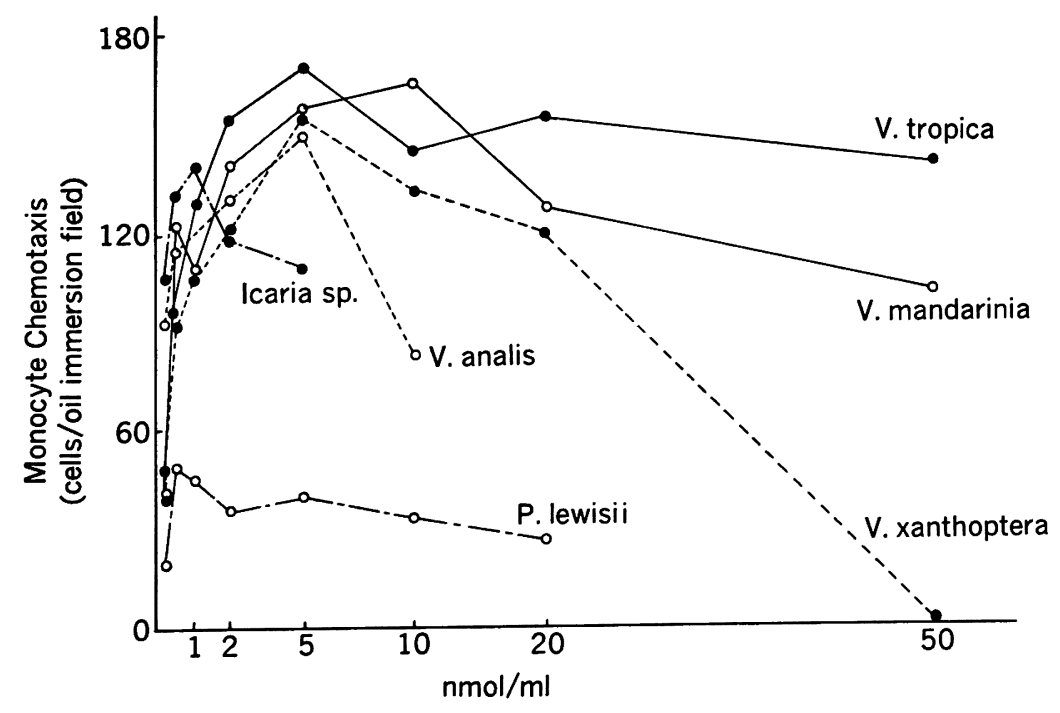

Fig. 1 Dose dependent monocyte chemotaxis to vespid peptides. Data represent the mean number of migrated cells per oil immersion field (20 fields counted). 


\section{References}

1) Yasuhara, T., Nakajima, T., Fukuda, K., Tsukamoto, Y., Mori, M., Kitada, G. and Fujino, M.: Structure and activity of chemotactic peptide from the venom sac of vespinae. Peptide Chem. Proc. 21st Symp. Peptide Chem. 185-190, 1983.

2) Falk, W., Goodwin Jr., R. H. and Leonard, E. J.: A 48-well micro chemotaxis assembly for rapid and accurate measurement of leuko- cyte migration. J. Immunol. Methods 33: 239-247, 1980.

3) Harvath, L., Falk, W. and Leonard, E. J.: Rapid quantitation of neutrophil chemotaxis: Use of a polyvinylpyrrolidone-free polycarbonate membrane in a multiwell assembly. J. Immunol. Methods 37: 39-45, 1980.

4) Tsukamoto, Y., Helsel, W. E. and Wahl, S. M.: Macrophage production of fibronectin, a chemoattractant for fibroblasts. J. Immunol. $127(2)$ : 673-678, 1981. 